\title{
Artículo
}

DOI 10.30972/nea.104548

Artículo recibido 25 de septiembre de 2020 Aprobado 15 de octubre de 2020

\section{Pandemia, circulación y "no antropocentrismo". La muerte como constructor de colectivos hipermediáticos: el caso del Dr. Duré en Chaco.}

\section{Pandemic, circulation and "non-anthropocentrism": death as a producer of hypermedia collectives: Dr. Dure's case in Chaco}

\author{
Silva Lotero, H. Nicolás \\ 1nicosilva@gmail.com \\ Facultad de Humanidades \\ Universidad Nacional del Nordeste (UNNE)
}

\begin{abstract}
Nicolás Silva Lotero es Técnico en Periodismo; se encuentra finalizando su tesis de graduación en la Licenciatura en Comunicación Social sobre circulación discursiva hipermediática en Corrientes y Chaco (2017-2020). Desarrolló tareas docentes como pasante y adscrito en las cátedras de Semiología de Comunicación Social I y II. Actualmente, su carrera profesional se desarrolla en medios gráficos correntinos. Fue organizador de proyectos audiovisuales y digitales.
\end{abstract}

\section{Resumen}

Este trabajo aborda el problema de la circulación discursiva durante la pandemia a partir del análisis de un caso particular: la muerte por coronavirus del médico Miguel Ángel Duré, jefe de terapia intensiva del Hospital público "Julio Perrando" de Chaco, Argentina, ocurrida el 19 de junio del 2020. Nuestra perspectiva teórica abreva en la sociosemiótica de raíz peirceana practicada por Eliseo Verón y las apropiaciones contemporáneas que viene realizando Mario Carlón. Nos interesa plantear la centralidad de los conceptos: mediatización, circulación y colectivos desde una perspectiva no antropocéntrica que dé cuenta de la interacción dinámica entre sociedad, naturaleza y máquinas.

Con una metodología que parte de considerar al discurso como una configuración espacio temporal de sentido con infinitos niveles de análisis, se ha conformado un corpus heterogéneo de materias investidas de sentido -publicaciones en redes sociales, conferencias televisivas, tapas de diarios, videos, fotografías- que conforman un paquete textual. Partiendo de allí describiremos el "viaje" del sentido desde el "momento cero" en Twitter. Tomando en cuenta sus cambios de escala y de dirección, compararemos los momentos más importantes de la circulación: el tuit del médico de guardia, las condolencias del gobernador Capitanich, la noticia en los medios masivos, los posteos de despedida en Facebook del compañero de internación y del hijo de Duré.

El análisis temporal y espacial mostrará cómo la circulación hipermediática implica una compleja interacción entre múltiples co-enunciadores que constituyen colectivos hipermediáticos donde el poder ya no reside en ciertos enunciadores tradicionales, como gobernantes y medios masivos, sino en la circulación misma. Otros enunciadores, como los internautas amateurs que administran sus propios medios, ahora tienen la capacidad de crear colectivos a partir del vinculo vida/muerte y del sentimiento de presente compartido. Anuncios de la llegada de la era contemporánea.

\section{| Palabras claves}

mediatización-circulación-colectivos-pandemia 


\section{| Abstract}

This work approaches the problem of discursive circulation during the pandemic through a particular case analysis: Dr. Miguel Ángel Duré's death from coronavirus. At the moment of his death on June 19th, 2020, Dr. Duré was the IC Unit Chief at Julio Perrando public Hospital in Chaco, Argentina. Our theoretical perspective lies on Pierce's socio-semiotic theory practiced by Eliseo Verón as well as on Mario Carlón's contemporary appropriation. We are interested in raising the centrality of the concepts: mediatization, circulation and collectives from a non-anthropocentric perspective that accounts for the dynamic interaction between society, nature and machines.

With a methodology that starts from considering discourse as a spatial-temporal configuration of meaning with infinite levels of analysis, a heterogeneous corpus of matters invested with meaning has been formed -postings on social networks, television conferences, newspaper covers, videos, photographs- that make up a textual package. Starting from there we will describe the journey of sense from the "moment zero" on Twitter. Considering its scale and direction changes, we will compare the most important moments of circulation: the tweet posted by the ER doctor on duty, the condolences by Governor Capitanich, the news in the mass media, and the farewells on Facebook posted by both Dure's hospital confinement partner and Dure's son.

The temporal and spatial analysis will show how hipermediatic circulation involves a complex interaction between multiple co-enunciators that constitute hypermedia collectives where power no longer resides in certain traditional enunciators, such as rulers and mass media, but in the circulation itself. Other enunciators, such as amateur Internet users who manage their own media, now have the ability to create collectives based on the life / death link and the feeling of the present shared. Announcements of the arrival of the contemporary era.

\section{Keywords}

mediatization-circulation-collectives-pandemy

\section{| Introducción}

Chaco, en el nordeste de la República Argentina, es una de las provincias argentinas más afectadas por el coronavirus, superando los $276^{1}$ fallecidos. El contagio comunitario llevó al sistema de salud al borde del colapso, con un importante número de sus trabajadores contagiados ${ }^{2}$. Las consecuencias de la demanda de atención de pacientes llevó a médicos, residentes y enfermeros a protestar de múltiples maneras por mejoras salariales y de las condiciones laborales ${ }^{3}$. El 30 de mayo de 2020, durante una marcha la Policía montó un cerrojo que restringió la movilización y multó a algunos profesionales por violar el aislamiento social preventivo y obligatorio ${ }^{4}$

1 Última actualización 25/09/2020 a las 18.40 .

2 Pieró C. (14 de abril 2020). En Chaco, más de la mitad de los contagiados con coronavirus son médicos, enfermeros y otros agentes de salud. Infobae. Recuperado de:

https://www.infobae.com/sociedad/2020/04/14/en-chaco-mas-de-la-mitad-de-los-contagiados-con-coronavirus-son-medicosenfermeros-y-otros-agentes-del-sistema-de-salud/

3 Hubo manifestaciones en la calle, denuncias públicas, posteos en cuentas personales de Facebook y hasta filtrado de conversaciones privadas con directivos vía audios de Whatsapp.

4 Multaron a médicos que marcharon por la precarización laboral (30 de mayo de 2020). Diario 21. Recuperado de:

http://www.diario21.tv/notix2/movil2/noticia/135677_multaron-a-los-meacutedicos-que-marcharon-contra-la-precarizacioacutenlaboral.htm 
En la madrugada del 19 junio de 2020 murió el doctor Miguel Ángel Duré, de 53 años, jefe del área de terapia intensiva del Hospital Perrando, el más importante centro de salud pública de la provincia, ubicado en la capital, Resistencia. Permaneció internado tres semanas, durante las cuales su caso tuvo cierta trascendencia en portales de noticias ${ }^{5}$ y en redes como Facebook o Twitter, donde un conocido periodista chaqueño, Julio Wajcman, le dedicó un tuit ${ }^{6}$. Duré, con 28 años de labor en la institución, se había contagiado de coronavirus a finales de mayo durante una cirugía de emergencia a un hombre que ingresó tras un accidente de tránsito. Después de la operación comprobaron que tenía coronavirus e infectó a 8 trabajadores de la salud, entre ellos Duré, y a 2 pacientes que compartieron sala $^{7}$.

Un colega de Duré, el doctor Julio Picón, se encontraba de guardia y empezó a comunicar a través de su cuenta en Twitter lo que había sucedido desde la madrugada, antes que los primeros portales de noticias. Ya por la mañana el gobernador de Chaco, Jorge Capitanich, dio sus condolencias usando sus perfiles oficiales en Facebook y Twitter, lo que desató una polémica entre otros usuarios. El caso siguió escalando en magnitud hasta llegar en pocas horas a noticieros y versiones online de diarios nacionales. También fue despedido en las redes por miles de internautas entre los que se destacaron dos: Ricardo Martínez, el joven médico que compartió sala de internación con Duré, y Matías Duré, el hijo.

\subsection{Marco teórico}

Desde diciembre de 2019 la humanidad se encuentra atravesando la mayor crisis civilizatoria del siglo XXI. Estamos ante lo que parece ser una alteración sistémica, cuyos síntomas venían siendo advertidos desde hace unos años y ahora ha estallado. Podemos asomarnos a esta cuestión mediante el problema de la contemporaneidad. Como se sabe, la modernidad fue declarada muerta hace cuatro décadas y como reemplazo, campeó la posmodernidad. Para Verón (2001) una sociedad mediática (moderna) es aquella donde los medios han comenzado a injertarse en el tejido social; ya en una sociedad mediatizada (posmoderna) los acontecimientos comienzan a construirse en torno a la función de los medios. En este sentido Verón (1994) llegará a proponer que los medios suplen al sistema político en crisis en la gestión del conflicto y la producción de cuadros identitarios.

Sin embargo, actualmente hay autores que sostienen que la posmodernidad fue un estado transitorio que ha quedado perimido y han comenzado a llamar a esta época -delimitada por el desarrollo y auge de la internet 2.0 y las "redes sociales"- contemporánea. El origen de este término proviene del Arte (como la posmodernidad, originada en la Arquitectura). ¿Qué caracteriza a la sociedad contemporánea? Desde nuestra perspectiva hay al menos tres rasgos fundamentales:

a. $\quad$ Ascenso de los sujetos a la producción discursiva mediática.

b. Coexistencia de dos sistemas mediáticos: el de los medios masivos y el digital.

c. Cambio de "régimen histórico": consolidación del presentismo.

5 La comunidad chaqueña ora por el médico Miguel Duré que contrajo coronavirus (6 de junio de 2020) Nova. Recuperado de: https://www.novachaco.com/nota.asp?t=La-comunidad-chaquena-ora-por-el-medico-Miguel-Dure-que-contrajocoronavirus\&id $=143608 \& i d \_$tiponota $=29$

6 https://twitter.com/juliowajeman/status/1269021817412485121

7 Se produjo diez nuevos contagios internos de coronavirus en el hospital Perrando (29 de mayo de 2020) Diario Chaco. Recuperado de: http://www.diariochaco.com/noticia/se-produjeron-diez-nuevos-contagios-internos-de-coronavirus-en-el-hospital-perrando 
Al encuadrar nuestro tema en la pandemia resulta sencillo plantear el otro aspecto del problema en el que estamos incursionando: la necesidad de contar con una perspectiva "no antropocéntrica" para poder continuar con un desarrollo teórico-metodológico capaz de estar a la altura de las crecientes complejidades. Jean-Marie Schaeffer (2007:14) en su obra El fin de la excepcionalidad humana plantea que la tesis (cuyo fin augura) considera que "en su esencia propiamente humana, el hombre poseería una dimensión ontológica emergente en virtud de la cual trascendería a la vez la realidad de otras formas de vida y su propia "naturalidad"' .

En La semiosis social. Fragmentos de una teoría de la discursividad, Verón desarrolla una sociosemiótica antropocéntrica $^{8}$ en la que propone una visión no lineal de la comunicación basada en el desfase perpetuo producción/reconocimiento siendo la circulación la instancia de esa diferencia (1987: 129). Sin embargo, influenciado por Schaeffer, en sus últimos trabajos Verón realizó considerables reelaboraciones y, acercándose a la teoría de los sistemas auto-organizantes de Luhmann (inspirados en la autopoiesis de Maturana y Varela), planteó el problema de los colectivos desde una perspectiva no antropocéntrica -aunque sin evacuar del todo los conceptos sociológicos-, dando a la mediatización (concebida como ruptura o salto de escala espacio-temporal por la cual el signo cobra autonomía y persistencia) una función clave en la relación entre lo que llamó sistemas socioinstitucionales y sistemas socioindividuales ya que la diferencia fundamental es que "la temporalidad de los sistemas socioindividuales es necesariamente la de un ciclo de vida orgánico. No es este el caso de los sistema sociales" (Verón, 2013:431).

Por su parte, Carlón sostiene que "las condiciones naturales imponen restricciones al discurso" (Carlón,2016a:12) y lo ha demostrado al estudiar el directo televisivo, donde no puede enunciarse flashforward como en el cine. Estos trabajos han dado relevancia al maquinismo: a la capacidad automática de las máquinas de producir sentido (Carlón,2009). Los medios masivos son máquinas creadas por la revolución industrial y en su desenvolvimiento han instalado en la sociedad una forma particular de enunciación que - valiéndonos de la tópica peirceana- es de carácter icónico-indicial, particularmente la fotografía, el cine y la televisión, y la radio. Agreguemos que estos medios ${ }^{9}$ siempre debieron acoplarse a nuestro equipamiento biológico (a nuestros cinco sentidos, principalmente a la vista) y deben incluirse dentro del largo proyecto artístico -nacido en la Antigüedad y retomada en el Renacimiento- de representar fielmente vida y naturaleza. Con el directo televisivo esta obsesión occidental alcanzó el grado máximo al no solo representarla sino quedar contaminada por ella al contener tiempo (Carlón,2016a:159).

El análisis y descripción que desarrollaremos tiene anclaje en la tesis según la cual naturaleza, sociedad y maquinismo están en permanente interacción. El coronavirus -enfermedad que hasta donde hoy se conoce tuvo origen en la naturaleza ${ }^{10}$ - construye colectivos sociales: "grupos de riesgo", "anti cuarentenas", "infectados", etcétera. Los colectivos son "construcciones que se producen en el seno de la comunicación" (Verón,1997:15) en cuya constitución no solo intervienen instituciones (Estado, familia, trabajo, universidad, etcétera) sino también procesos mecanísticos autónomos como los algoritmos $^{11}$, y también procesos naturales. El caso del doctor Duré es un ejemplo de la relevancia del vínculo vida/muerte en la construcción de colectivos con múltiples enunciadores de distinto estatuto, configurados en el interior de un dispositivo de enunciación productor de una discursividad que circula de las redes a los medios y viceversa.

8 Recordemos la doble hipótesis sobre el sentido: toda producción de sentido es necesariamente social y a la vez todo fenómeno social tiene una dimensión constitutiva como producción de sentido.

9 Seguimos aquí la noción veroniana de medio como tecnología de la comunicación (o de la producción-circulación-recepción de mensajes) que se articula con prácticas sociales y cuyo acceso es de carácter público, más allá de que sea pago o no.

10 Ballarino F. (21 de septiembre de 2020). Es falso que una viróloga china haya probado que el coronavirus fue creado en un laboratorio. Chequeado. Recuperado de: https://chequeado.com/el-explicador/es-falso-que-una-virologa-china-haya-probado-que-elcoronavirus-fue-creado-en-un-laboratorio/

11 Por ejemplo el que opera en la "autoevaluación de salud" de la aplicación gubernamental Cuidar. 


\section{| 1.2. Metodología}

Partimos de las premisas metodológicas de la imposibilidad de un análisis inmanente del discurso y del desfase constitutivo entre producción y reconocimiento. Por lo tanto nos basaremos en la comparación de materialidades investidas de significación que conforman un "paquete textual". Para Verón el discurso es una configuración espacio-temporal de sentido analizable en infinitos niveles, dependiendo de la posición que adopte el analista-observador, y cuál sea su interés: "un discurso, cualquiera que fuere su naturaleza o tipo, no refleja nada; él es solo punto de pasaje del sentido" (Verón, 1987:128).

El corpus está constituido por un conjunto heterogéneo de materialidades: capturas de pantalla de publicación en Twitter y Facebook (posteos y comentarios), noticias de portales web y de versiones online de diarios, tapas de diarios impresos, fotografías, grabaciones de transmisiones televisivas en directo, videos subidos a Facebook, Twitter y Youtube. La coherencia interna está dada por el haz de preguntas con que el investigador lo atraviesa. A la unidad de análisis la denominamos: circulación discursiva hipermediática en Chaco 2020.

Utilizaremos dos esquemas. El temporal: una línea de tiempo que parte en el origen de la mediatización del sentido hasta un punto determinado de la circulación en la que el analista considera pertinente cortar. El espacial: gráficos comparativos que muestran la disposición de los integrantes del colectivo en los distintos momentos importantes de la circulación.

La elección del caso ha sido responsabilidad del investigador, una decisión arbitraria que se justifica por su relevancia y las posibilidades de una descripción densa de un proceso de circulación contemporánea. Es el analista el que selecciona los momentos ${ }^{12}$-denominados fase o subfase- por reunir las características de un salto hipermediático. "Hay al menos tres transformaciones sistémicas en los saltos hipermediáticos:a) cambios de escala en la mediatización, b) complexificación de las direcciones comunicacionales, y c) cambios de estatuto del enunciador o de los vínculos entre los enunciadores y los enunciatarios" (Carlón, 2019:34).

\section{| El análisis}

\subsection{Duré, metonimia y crisis sanitaria}

En la mediatización de la muerte del Dr. Duré subyace una operación metonímica: una de las víctimas del coronavirus se pone en lugar del conjunto, significando así la crítica situación que atraviesa la comunidad. La lógica metonímica (indicial) encuentra en el cuerpo al soporte y operador del sentido. Verón remarca la importancia del cuerpo como pivote de la "capa metonímica de la producción de sentido", como "operador fundamental de esta tipología del contacto" ( Verón, 1987: 141).

La corporeidad (ausente y presente) de Duré cobra relevancia como referente por su dimensión biológica, por su finitud, y se engarza a una carga semiótica heterogénea pero centrada en el sentimiento de de co-presencia. Se configura así un dispositivo de enunciación con múltiples enunciadores productores de una discursividad pasible de ser analizada a nivel pasional y político. Con la noción dispositivo de enunciación se se busca evacuar cualquier subjetivismo o psicologismos (que en última instancia deriva del cogito cartesiano) que pretendan considerar al sujeto enunciador como fuente del sentido a la manera de Benveniste (1966) y Kerbrat-Orecchioni (1980). "Toda palabra enuncia un 
contenido y, al mismo tiempo, se muestra (podríamos decir, fatalmente) inscripta en un dispositivo enunciativo que sobredetermina lo que es dicho (...) El actor no es una entidad fantasmática: no es sino la red de relaciones enunciativas materializadas en el interdiscurso" (Sigal y Verón, 2009:252).

\section{| 2.2. Los hilos del Dr. Picón}

El punto de inicio de la circulación corresponde a las 1:26 am, cuando desde su cuenta personal de Twitter el médico cirujano, Julio Picón (@drjuliopicon), tuitea el siguiente mensaje:

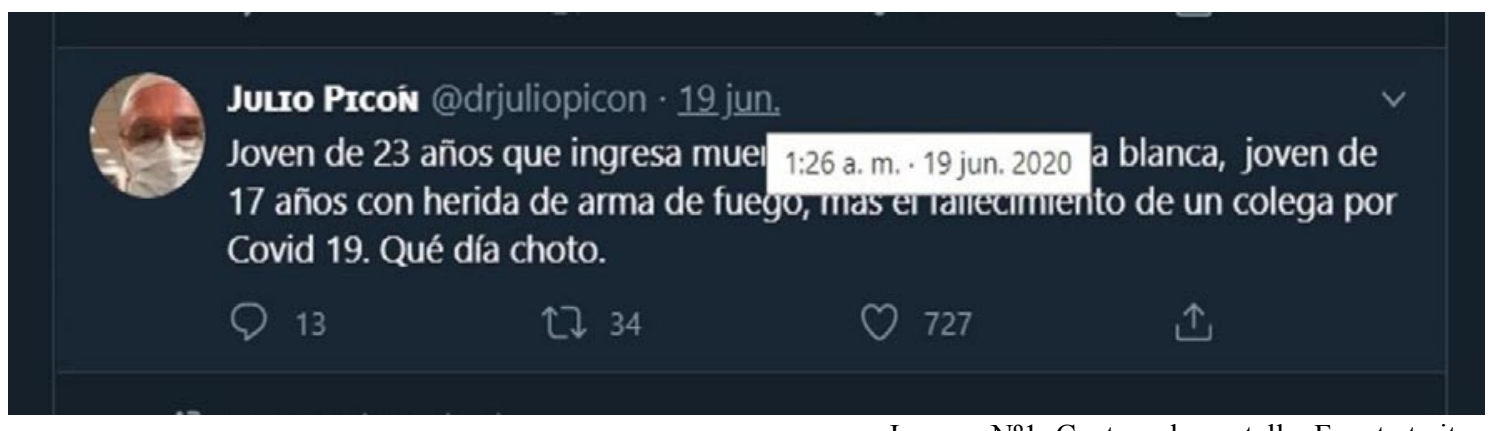

Imagen $\mathrm{N}^{\mathrm{o}}$ 1: Captura de pantalla. Fuente:twiter.

Picón es médico cirujano del Hospital Perrando y desde abril de 2013 utiliza Twitter. Es habitual que tuitee sobre lo que sucede en sus guardias nocturnas, incluyendo fotografías de heridos, con una fuerte carga humorística. Si bien "habla" de otros temas su discurso pasa fundamentalmente por su rol de médico. Es esto lo que instala un "pacto" con los otros internautas, que creen que él es en las redes lo que -en cierto nivel- es en el "afuera" (Carlón, 2020:109). Picón es un enunciador "amateur", uno de los millones que ha accedido a la producción discursiva mediática merced a la digitalización e internet. Ha construido un ethos virtual que se caracteriza por no diferir del extra-discursivo. Es cierto que estuvo en el momento y lugar pero sí produjo tal efecto de autenticidad fue debido a que ya existía un vínculo de creencia con seguidores y no seguidores.

Agreguemos que la circulación es "transversal". Lo que se mediatiza es el exterior: se introduce a las redes un contenido que es propio de la administración de una institución no mediática. La producción discursiva en general, y este caso en particular, del @ drjuliopicon consiste en hacer "público" elementos discursivos cuya circulación estaba antes bajo la gestión exclusiva de la institución:

Los individuos mediatizados no solo intercambian discursos entre sí a través de distintas "redes sociales mediáticas". También se encuentran "adentro" de todas las instituciones, medios y colectivos, porque instituciones, medios y colectivos están compuestos por individuos. Por consiguiente los contenidos ahora no van "hacia afuera" sólo desde los voceros o los medios institucionales de partidos políticos, empresas, iglesias, fuerzas armadas, etcétera, como lo hacían en la modernidad y la posmodernidad. Eras en las que acceder a información del "interior" de instituciones era excepcional. También lo hacen cotidianamente desde los "medios individuales" que administran quienes forman parte de cada institución. Y no sólo llegan "hacia adentro", desde los medios masivos a las instituciones. También lo hacen desde los "medios individuales" y desde los "medios colectivos" emplazados de las redes sociales mediáticas. Es decir en puntos de encuentro entre la circulación verticalhorizontal y la transversal en los que se producen un conjunto de cambios de escala y de transformaciones (Carlón, 2020:169). 


\section{Volumen 1

En la imagen $\mathrm{N}^{\mathrm{o}} 1$ advertimos que la puesta en conocimiento de la muerte de Duré está incluida en una terna de incidentes que llevaron a Picón a poner el calificativo "choto" a su turno de guardia. El tuit genera un "hilo" donde otros internautas, despiertos a esa hora de la madrugada, empiezan a entablar una comunicación con Picón, interesados en saber quién era el "colega" que había muerto. "Médico del Hospital Perrando", añadió en una de sus primeras intervenciones. Luego de 14 minutos del primer tuit la usuaria @Karengonzzzzz pregunta: “El doc dure?”. En respuesta al "Si” del doctor Picón,@Karengonzzzzz, comenta: “Qepd el doctor Duré. Padre de un alumno del mismo colegio que mi hijo". La frase incluye dos emojis: la carita triste con una lágrima y corazón roto. Advertimos aquí una "relación de alteridad con respecto al co-enunciador" (Culioli, 2010:114) como una característica del enunciador Dr. Picón, una relación dinámica que supone la actividad, no solo del enunciador sino de co-enunciadores, mediante operaciones de ajuste, como las que pueden apreciarse en en esta suerte de acertijo que fue decifràndose por la interacción de Picón y los comentadores del tuit.

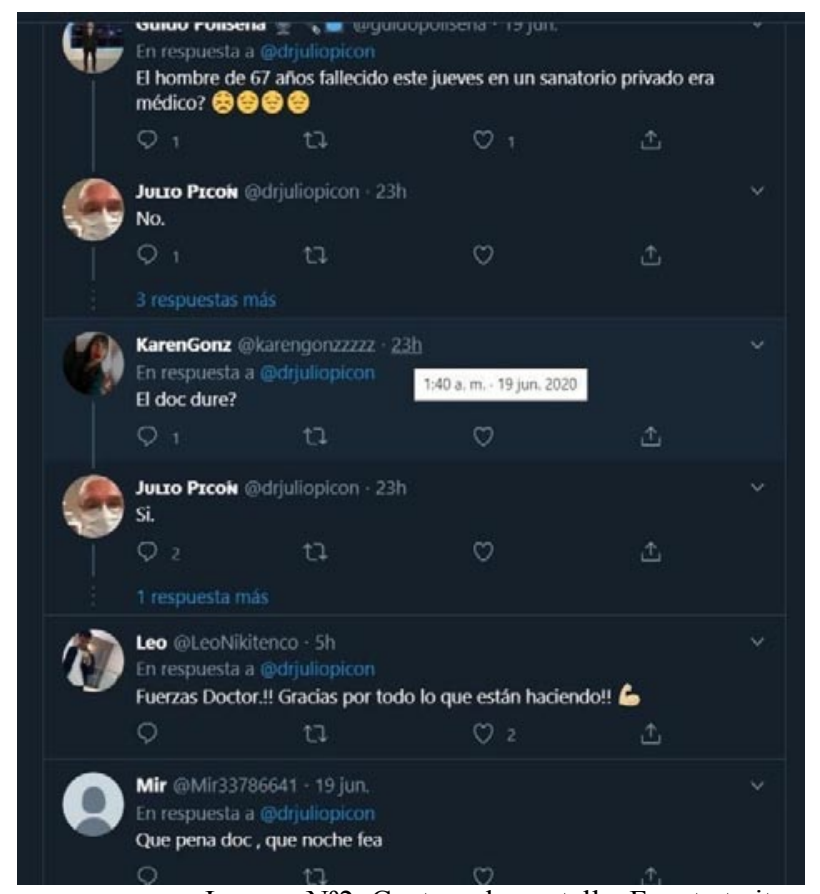

Imagen $\mathrm{N}^{\circ}$ 2: Captura de pantalla. Fuente:twiter.

Observamos como en este primer momento de la circulación, la dirección es claramente contemporánea: el enunciador y sus co-enunciadores entablan una comunicación "horizontal"; hay preguntas y respuestas; también, mensajes de aliento. En la imagen $\mathrm{N}^{\mathbf{0}} 2$ advertimos ya la "materialización" de la circulación, la diferencia queda expuesta ${ }^{13}$. Notemos también que ha comenzado a conformarse un colectivo en torno al mismo foco de interés.

A las 3:10 am el doctor Picón publica una fotografía tomada con celular. La imagen es vertical, escenificada en el corredor de un pasillo del hospital. A tres metros de la posición del fotógrafo, un cadáver envuelto en una sábana sobre una camilla, trasladada por un enfermero a quien apenas se le ve un brazo, la manga del ambo azul y el guante blanco de látex de su mano: 


\section{Volumen 1 \\ "Semiótica en Tiempos de PANDEMLA y POS/PANDEMLA"}

Revista del grupo de Estudios SEMTO-DISCURSNOS

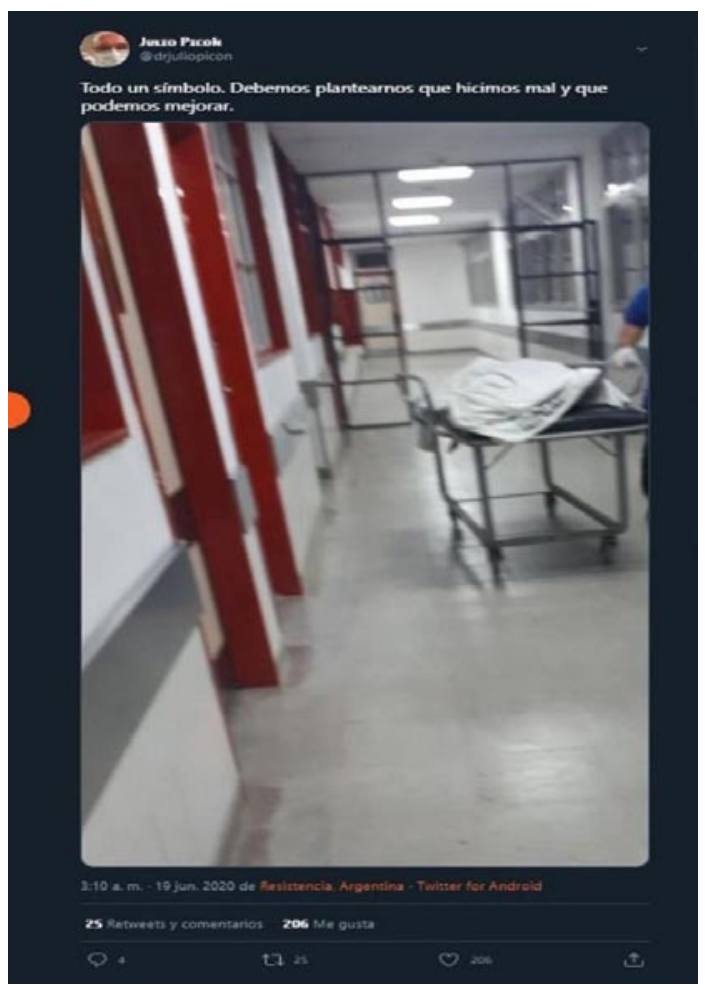

Imagen $\mathrm{N}^{\circ}$ 3: Captura de pantalla. Fuente:twiter.

“Todo un símbolo", empieza la frase del tuit. Picón evita explicitar la identidad del fallecido, hace una elipsis. Sin embargo, en reconocimiento no hay dudas de que es Duré. Se ha convertido en "símbolo" aunque este enunciado coincide con la operación metonímica antes referida. La fotografía porta las propiedades icónico-indiciales de verosimilitud de ser una representación del cuerpo de Duré, por la semejanza morfológica pero sobre todo por la creencia de una relación existencial con el referente ${ }^{14}$. Como lo señala Carlón (2015) pese a estar sometida a condiciones contemporáneas de circulación, la fotografía sigue "capturando" el tiempo no "conteniéndolo" como el directo, si se la tomó en el instante previo a subirla por @drjuliopicon, o en el transcurso de las dos horas que transcurrieron desde el primer tuit, la imagen fotográfica siempre enuncia "esto ha sido". Nos enfrentamos a un "muerto".

A las 5:30 am el doctor Picón tuitea otro "hilo" en el que arranca así: "Justo me tocó guardia hoy, y sabía que estabas mal. Que habías hecho un neumotórax bilateral y veíamos la placa en la computadora, y sabíamos el pronóstico. Tratamos de no pensar en eso, y seguimos atendiendo pacientes, heridos, etc. Es un número que se incrementa día a día ${ }^{15} "$. La publicación alcanza los 1.105 retuits y 3.800 likes. El hilo prosigue con otras 6 publicaciones donde Picón refiere a los problemas en el sistema sanitario de Chaco y los define como "una estela de hechos desafortunados que va dejando una estela de muertos". Menciona falta de insumos (como los barbijos $\mathrm{N}^{0} 96^{16}$ ), peleas entre directivos y residentes. "La duda te invade: vale la pena tanto sacrificio?", se pregunta. "Y al final te das cuenta, que como médico y personal del hospital sos reemplazado por otro, y que los únicos que van a recordarte siempre, eternamente, va a ser ese núcleo reducido, casi anónimo de tu familia. Que en paz descanses Dr. Miguel Ángel Duré”, dice el último mensaje.

14 La extensión de este artículo vuelve imposible una comparación específica de las fotografías que circularon en este caso.

$15 \mathrm{https} / /$ twitter.com/drjuliopicon/status/1273895933470666752

16 Situación precaria en Chaco: no cuentan con barbijos ni antiparras suficientes (19 de marzo de 2020) Radio Lt7. Recuperado de: http://www. radiolt7.com/noticia/2-64313-situacioacuten-precaria-en-chaco-no-cuentan-con-barbijos-ni-antiparras-suficientes.htm 
Picón replicará el mensaje en su cuenta de Facebook a las 5:54 am. Repercutirá en 4.203 compartidos y recibirá cientos de comentarios, en los que otros internautas se solidarizan y envían "abrazos", piden permiso para compartir o resaltan la "claridad" de la reflexión. Dos cuestiones sobresalen: por un lado el pasaje de Twitter a Facebook supone un cambio tanto por las "restricciones" de cada superficie mediática como porque en una y otra red el enunciador se presenta de forma distinta ${ }^{17}$. Por otro lado, la dirección comunicación "horizontal" se ve afectada, al desplazarse el enunciador operando un cambio del registro- en reconocimiento del discurso que había mediatizado: la muerte de Duré lo lleva a "ponerse en su lugar".

Se externaliza un proceso mental en la mediatización: no solo podemos "saber" o conocer lo que por esas horas cavilaba Picón sino "sentir" ya que su mensaje habilita la "compasión". Así, por ejemplo@floander comentó “por dios, me hizo llorar ese tuit ${ }^{18}$ ”, o @puelo_azul, que comentó: "Usted describió este momento como nadie Qué tristeza y cuanta verdad hay en este hilo. Le tengo un profundo respeto ${ }^{19}$ ',

A las 11:30 am Picón sube un video a Twitter acompañado de la frase: "Un nudo en la garganta ${ }^{20 ",}$ el material también será subido 4 minutos más tarde a su perfil en Facebook. El video dura 33 segundos y es filmado afuera del Hospital Perrando, se ve pasar un coche de la funeraria conducido por un hombre con escafandra amarilla y luego otros tres vehículos. En la vereda se ven médicos y enfermeros aplaudiendo. La grabación tenía más de 54 mil reproducciones. También subirá una foto de los médicos y enfermeros fuera del hospital, de pie aplaudiendo el cortejo que se retira del lugar. Y otro video -a las 11:32 am - de una "marcha del silencio" del personal de salud alrededor del edificio.

Intentando esquematizar lo hasta aquí descrito y valiéndonos del esquema temporal propuesto por Carlón ilustramos el primer momento de la circulación (fase 1) de la siguiente manera:

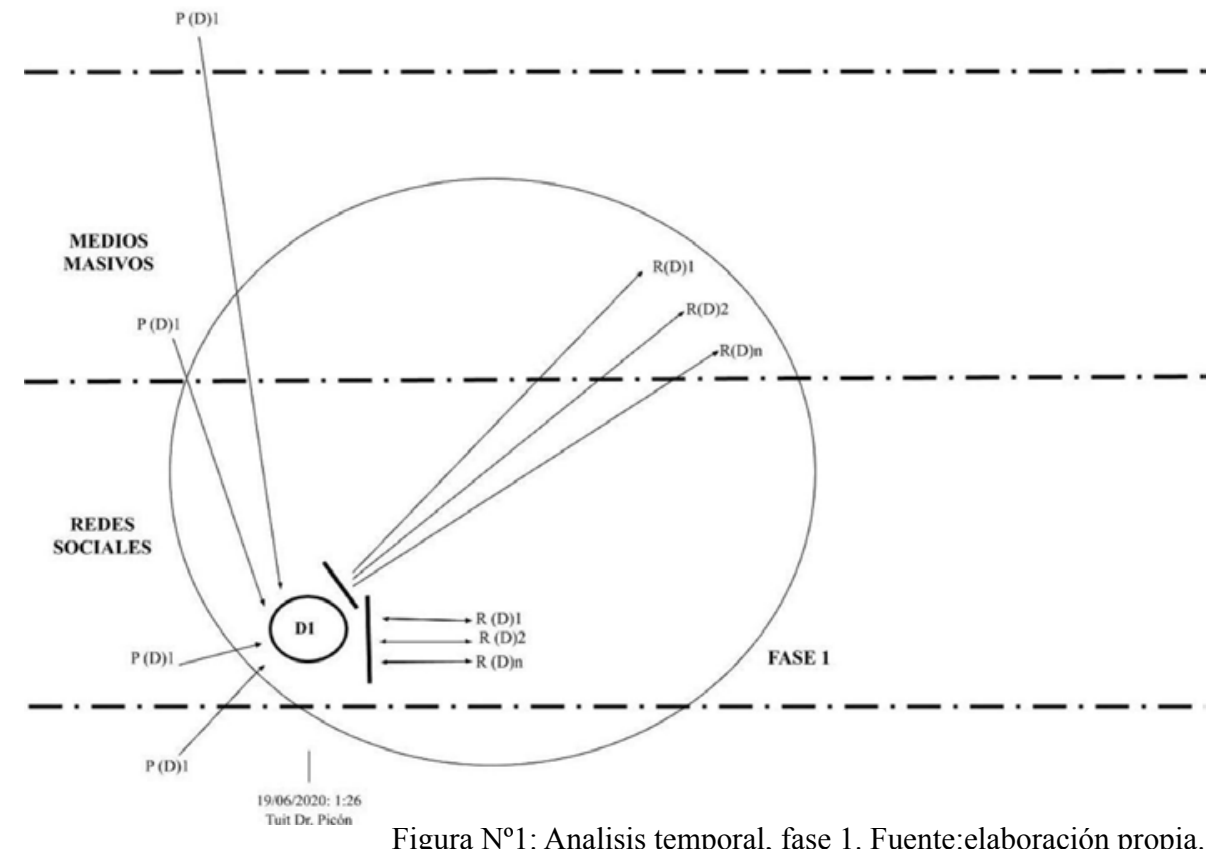

17 Hay elementos comunes en cada cuenta (por ejemplo en ambas portadas hay fotos familiares) sin embargo casi no hay fotos de los pacientes heridos en las guardias nocturnas, aunque sí varias de Picón trabajando (incluyendo selfies). Esto se debe, al menos en parte, a las "dinámicas" de cada red mediática.

$18 \mathrm{https} / /$ twitter.com/floanders/status/1274024895589101568

$19 \mathrm{https}: / /$ twitter.com/puelo azul/status/1274074779872608256

$20 \mathrm{https} / / /$ twitter.com/drjuliopicon/status/1273985704515731456 
Advertimos que a lo largo de las 10 horas en que Picón participó activamente, la "conversación" fue alternándose. Lo particular es el cese de las respuestas a los comentarios, pasando el "coenunciador" Picón a una función enunciativa si se quiere "meta". De lo anterior no debe entenderse que se haya producido un cambio radical en la dirección comunicacional, la cual sigue siendo típicamente contemporánea, sino que al ir ampliándose el colectivo en torno al sentido su principal enunciador hasta ese momento se ve llevado por el dispositivo a ocupar una función enunciativa que podríamos denominar de "grado 2" mientras que los "co-enunciadores" son puestos en una enunciación de "grado 1" (Carlón, 2020). Los enunciadores "grado 1" participan, comentan, "hablan" entre sí, se preguntan, discuten o manifiestan su coincidencia con una opinión previa pero el "salto hipermediático" lo dan los hilos y el posteo en Facebook de Picón que son retomados por los medios masivos ${ }^{21}$.

\section{| 2.3. Las condolencias de Capitanich}

A las 8:50 am del 19/06/2020 el gobernador de Chaco, Jorge Capitanich, a través de sus cuentas oficiales en Facebook y Twitter emite un comunicado con sus condolencias por el fallecimiento del doctor Duré:

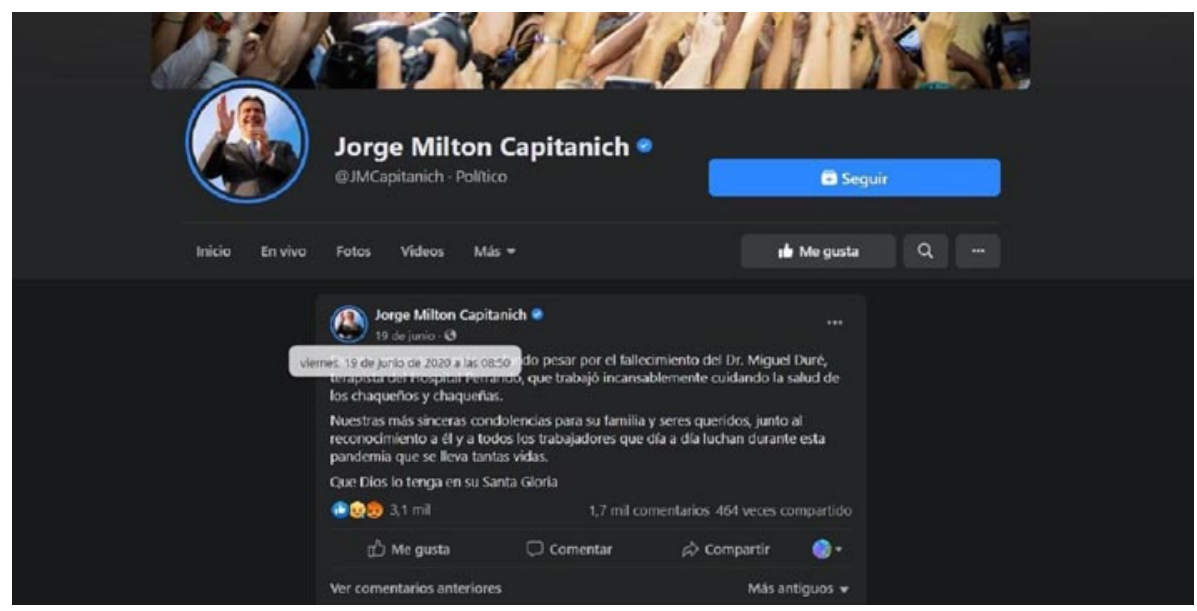

Imagen Nº4: Captura de pantalla. Fuente:Facebook.

Nos encontramos aquí ante un salto de escala en la circulación del sentido: la fase 2. Comparado con la fase anterior esta se diferencia por el enunciador, ya no es un amateur sino un "profesional"22, con la particularidad de ser una encarnación virtual de la institución estatal. Su comunicación no es horizontal, pese a ser enunciada por las redes no entabla una relación entre pares. El posteo, si bien tiene en sus condiciones de producción una lógica institucional, es personal ya que se publica en las cuentas oficiales de Capitanich. Esto implica salirse de los marcos institucionales tradicionales (conferencias, gacetillas, entrevistas periodísticas, etcétera) para actuar en una arena comunicacional muy distinta y de mayor exposición.

21 Fragmentos de los tuits de Picón fueron insertados en esta nota publicada el 19/06/2020 a las 15:42 pm en la versión on line del diario La Nación. Coronavirus, Murió el jefe de Terapia en Chaco y reavivó las denuncias por el manejo de la pandemia (19 de junio). Recuperado de: https:/www.lanacion.com.ar/sociedad/coronavirus-murio-jefe-terapia-intensiva-chaco-reavivo-nid2382580

22 Las redes sociales del gobernador de Chaco, como la de muchos políticos, es administrada por un equipo de comunicación, integrado en gran medida por egresados de la licenciatura de Comunicación Social (UNNE). Esto es importante para erradicar cualquier idea de "subjetividad" en la enunciación. 
La intervención de Capitanich en la circulación del sentido afectó al colectivo. Al ser el representante del gobierno, considerado uno de los responsables de la muerte de Duré, su discurso es leído en reconocimiento en múltiples registros. Como afirma Maingueneau el ethos implica un "tono" que se relaciona con un "conjunto de representaciones sociales difusas" sobre el que el enunciado y el cuerpo del enunciador se apoyan (Maingueneau,2009:91). Capitanich construye así una imagen doble: la del gobernante y la del creyente. Expresa su "pesar" y da sus "más sinceras condolencias". Como gobernante exalta la figura de Duré y reconoce a "todos los trabajadores que día a día luchan durante esta pandemia" pero, en el último tramo de la enunciación, vira hacia lo personal (religioso) y pide: "Que Dios lo tenga en su Santa Gloria". El ethos de Capitanich apela a dos tipos generales de "representaciones": el político y el cristiano. Ello no implica que en reconocimiento estas representaciones están separadas o se excluyan, al contrario se las puede hallar unidas.

Verón (1987) propone distinguir tres posibles destinatarios de la discursividad política: prodestinatario, contra-destinatario y para-destinatario. Todo discurso político crea un adversario, esto ya se veía reflejado en la instancia anterior de la circulación pero en esta fase adquiere toda su relevancia con la aparición enunciativa en la "escena semiótica" de Capitanich, quien ya había sido nombrado como "contra-destinatario". Con su enunciación hay un giro en el sentido y las posiciones se reacomodan.

Siguiendo esa tematización veroniana, Ana Slimovich(2012) analizó las cuentas de Facebook de Cristina Fernández de Kirchner y Mauricio Macri durante el período 2010-2011 llegando a una clasificación de siete modalidades discursivas de los comentaristas (Slimovich,2012:148-150). Aplicando esta clasificación a la publicación de Capitanich hallamos las siguientes:

-Seguidores argumentadores pasionales: "Expresan su admiración y militancia”(149)

Lidia Esther Vallejos

Usted no tiene nada k ver. Hay gente $\mathrm{k}$ todavia no saben

lo k esta pasando $\mathrm{k}$ no reacciona. $Y$ culpa a quien no es. solo DIOS TODO PODEROSO LO SABE. Y contra el no podemos...

Me gusta - Responder $\cdot 3 \mathrm{~h}$

Imagen $\mathrm{N}^{\circ}$ 5: Captura de pantalla. Fuente:Facebook.

-Seguidores argumentadores lógicos: "constituyen un discurso político, argumentan a favor del gobierno y a la vez construyen contra destinatarios (148)

Viviana Escobar

La gente ciega por el odio,que se callo 4años,aun cuando cerraban el ministerio de salud ninguno de los q habla en contra del gobernador,politiqueria barata,quedaron restos de la mafia macrista aca tambien.

Me gusta $\cdot$ Responder $\cdot 3 \mathrm{~h}$ 


\section{Artículo}

Revista del grupo de

Estudios SEMTO-DISCURSNOS

-Comentaristas interpretadores: "Contestan los comentarios del resto de los usuarios, replicando argumentaciones" (150)

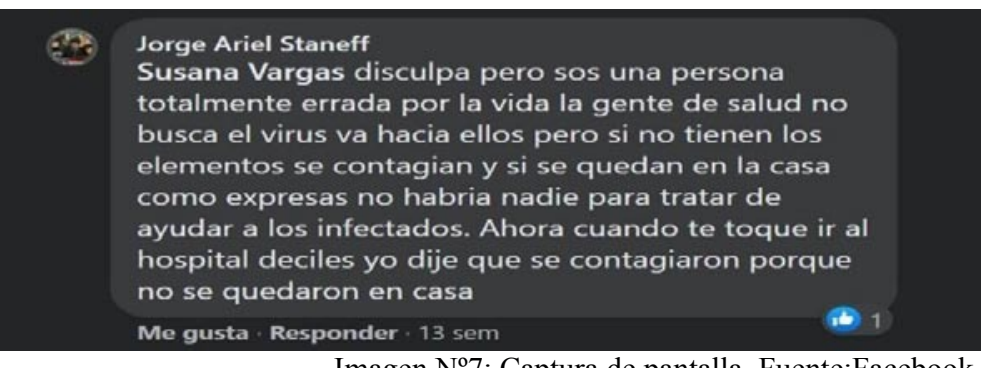

Imagen Nº: Captura de pantalla. Fuente:Facebook.

-Opositores argumentadores: "Construyen discurso político argumentan contra el gobierno sin manifestar su adhesión a otro partido o candidato" (149)

\section{El doctor Dure murio x tu culpa Caputanich..x tu deseo ilimitado d plata y poder..x tu mala y corrupta gestion....en nombre d estos eroes pedi disculpAs y presenta tu renuncia junto con la inutil d tu ministra $d$ salud}

Nancy Lorena

Imagen $\mathrm{N}^{\mathrm{o}}$ 8: Captura de pantalla. Fuente:Facebook.

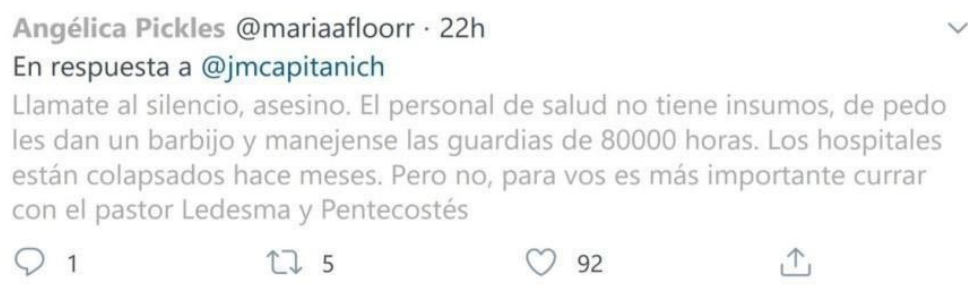

Imagen $\mathrm{N}^{\circ}$ 9: Captura de pantalla. Fuente:Twiter.

-Comentaristas demandantes: "Hacen pedidos o consultas sin referencia al tema" (150)

Ema Rios

Señor Gobernador le pedimos más control en los barrios aquí en Villa Don Andrés, fiestas en flia, con niños, son barbijos,desde el mediodia hasta la noche..por favor...que haya un control..cruzan los puentes cerrados caminando,no los controlan si son d... Ver más

Me gusta $\cdot$ Responder $\cdot 2 \mathrm{~h}$

Imagen $\mathrm{N}^{\circ} 10$ : Captura de pantalla. Fuente:Facebook. 


\section{Volumen 1 \\ "Semiótica en Tiempos de PANDEMLA y POS/PANDEMLA"}

\section{Artículo}

Revista del grupo de

Estudios SEMIO-DISCURSNOS (150)

-Seguidores imitadores: "Replican los motivos temáticos que aparecen en el post del gobernante"

Floreria Vivero Virgen DEL Rosario

Q.E.P.D. DR MIGUEL DURE, Y MIS CONDOLENCIAS

FAMILIARES, AMIGOS, COLEGAS Y PACIENTES,

Imagen $\mathrm{N}^{\circ} 11$ : Captura de pantalla. Fuente:Facebook.

-Seguidores comentadores: "Argumentan a favor de la gestión pero no configuran un adversario político"(150).

Mariangeles Edith Nuñez

un poco de MISERICORDIA TODOS sentimos la muerte del dr Dure pero en todo el mundo paso esto.es el riego lamentable que están expuestos nuestros médicos $Y$ enfermeros y que estén protegidos por el amor de DIOS.Dios nos da la vida hasta que nos llama y ... Ver más

Me gusta $\cdot$ Responder $\cdot 2 \mathrm{~h} \cdot$ Editado

Imagen $\mathrm{N}^{\circ} 12$ : Captura de pantalla. Fuente:Facebook.

La modalidad opositores argumentadores es la más reiterada en Facebook (en Twitter se vuelve predominante en casi ausencia de seguidores argumentadores). Sin embargo, el colectivo en torno a la comunicación está compuesto de un conjunto heterogéneo de co-enunciadores que interpelan por igual al gobernante. Así es apreciable como la intervención de Capitanich modifica las posiciones previas al interior del colectivo generando un reflujo en las corrientes antagónicas definibles entre quienes lo responsabilizan por la muerte de Duré y quienes lo exculpan (profundizaremos esto al aplicar el esquema espacial en ítem 2.7.). Además hay retoma por parte de los medios masivos, con énfasis en el "rechazo" 23 ".

Intentando representar este momento de la circulación, denominado fase 2, esquematizamos la siguiente figura:

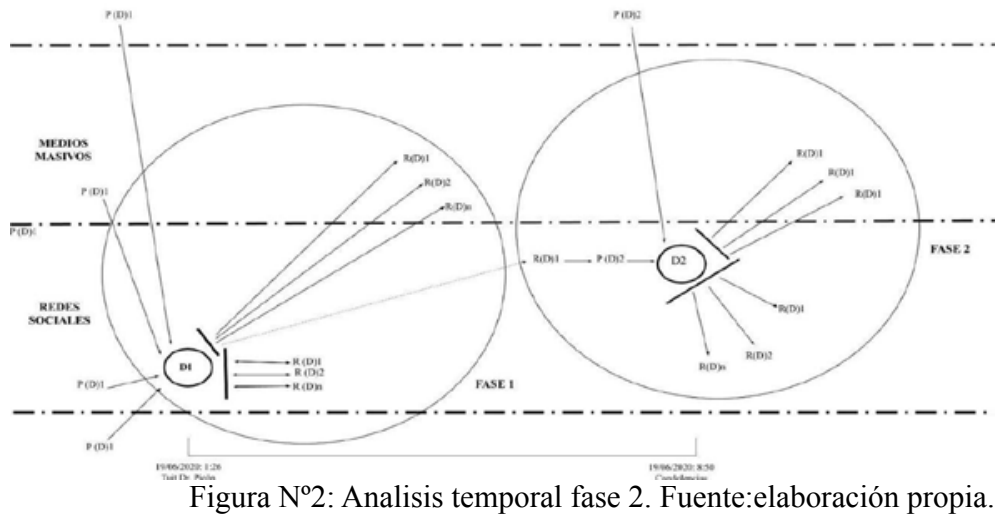

23 Rechazo de la comunidad tras las condolencias de Capitanich por Duré (19 de junio 2020). Data Chaco. Recuperado de: https://www.datachaco. com/rechazo-la-comunidad-las-condolencias-capitanich-dure-n146163 
Lo que nos parece interesante es cómo el poder de la circulación se impone por sobre el poder del enunciador. "Cuando se trata de dar cuenta, en el interior de un proceso determinado de circulación, de los efectos de sentido de un conjunto significante dado (...) nos enfrentamos a la cuestión del poder" (Verón,1984:48). Capitanich quedó expuesto a las condiciones de circulación contemporánea y recibió un fuerte repudio de una parte mayoritaria de los comentaristas y hasta otras formas de apropiación humorísticas como el meme ${ }^{24}$. Carlón (2016a:41) recuerda que los marcos institucionales están creados para que el gobernante no quede expuesto al ridículo o lo inesperado. Algo que aquí ocurrió. En parte se debe a que en toda mediatización hay descontextualización, pero además porque en las redes mediáticas las relaciones de poder -que son relación de comunicación (Castell, 2009)- la asimetría entre los enunciadores se "nivela" y la circulación del sentido se vuelve el factor a atender:

Hay dos fenómenos que no pueden soslayarse hoy. Por un lado que mucho más que antes los enunciadores poderosos están siendo sometidos en espacios públicos mediatizados a flujos de sentido novedosos, generados por otros enunciadores, que relativizan constantemente su poder. Por otro que hay múltiples enunciadores que no son poderosos en situaciones pre-existentes pero que sí lo son en las redes y en la circulación hipermediática, porque son capaces de generar saltos hipermediáticos, construir colectivos y generar manifestaciones de colectivos en espacios públicos que escapan al radar analítico que privilegia al poder. Es que la circulación contemporánea se ha vuelto un escenario dinámico y complejo en el que los flujos de sentido ya no solo provienen de los enunciadores tradicionales, sino también de otros que construyen de modo diferente su legitimidad y que desencadenan otros procesos de circulación (Carlón, 2020:101).

\section{| 2.4. Salto hipermediático}

El sentido mediatizado pasa del sistema de medios digitales a medios masivos desde la madrugada del 19 de junio de 2020 cuando portales de noticias chaqueños se hacen eco de la muerte de Duré. La primera información data de las 2:03 25 am pero el flujo irá creciendo durante el resto del día e incluso persistirá en los posteriores. Estas retomas son características de la circulación hipermediática (Carlón,2020:131) y alcanzan el pico después del mediodía cuando medios nacionales consignan la noticia. A las 15:42 pm la versión online del diario La Nación publica la noticia, también para esa hora el caso repercutió en las portadas de los sitios Clarín. $\operatorname{com}^{26}$ e Infobae ${ }^{27}$. Los noticieros de la Televisión Pública, C5N, América 24, TN, Canal 26 y el canal estatal de Chaco (Chaco Tv) emitieron breves informes, incluyéndose en su agenda del día. Al día siguiente esta fue tapa de los cuatros diarios de Chaco y en dos de la vecina ciudad de Corrientes ${ }^{28}$, algunos de los cuales incluyeron fotografías de la manifestación de los médicos y ciudadanos frente al Hospital Perrando durante la tarde del 19 de junio en homenaje a Duré29 .

24 Incluso hubo memes. Puede consultarse: https://www.facebook.com/CorrientesSp/posts/267622458010835

25 Falleció el terapista Miguel Dure (19 de junio de 2020) Data Chaco. Recuperado de: https://www.datachaco.com/fallecio-el-terapista-miguel-duren146155

26 La muerte del jefe de terapia intensiva en Chaco reavivó el reclamo por la falta de insumos hospitalarios (19 de junio de 2020) Clarín. Recuperado de: https://www.clarin.com/sociedad/muerte-jefe-terapia-intensiva-chaco-reavivo-reclamo-falta-insumos-hospitales_0_5TzD0c04u.html

27 "Un héroe sin capa": el conmovedor homenaje al jefe de terapia intensiva en Chaco que murió por coronavirus (19 de junio de 2020 ). Infobae. Recuperado de: https://www.infobae.com/coronavirus/2020/06/19/un-heroe-sin-capa-el-conmovedor-homenaje-al-jefe-de-la-terapia-intensiva-en-chacoque-murio-por-coronarivus/

28 Por razones de espacio resulta un análisis pormenorizado de estos elementos discursivos en sus particularidades. Esperamos poder concretarlo en la investigación de tesis en curso.

29 Aquí el lugar es insuficiente para desplegar el aspecto de la manifestación pero digamos al menos que es una parte del colectivo configurado en las redes que se movilizó en las calles, lo que nos lleva a remarcar la necesidad de un estudio más profundo que considere tanto lo que pasa en el online como en el offline. 
También los medios masivos dieron a conocer una "carta pública" de los residentes del Hospital Perrando: "Fallaron. El sistema de salud falló. Este es el resultado. Personal de salud infectado. Un médico que ya no está", dice el escrito conformado de 6 párrafos breves pero lapidarios ${ }^{30}$. Esta respuesta discursiva en clave política -señalando la responsabilidad del gobierno en la muerte de Duré- no fue publicada primero en las redes mediáticas sino que directamente apareció en los medios masivos. Operó aquí la lógica posmoderna de que los hechos "no existen en tanto tales (en tanto hechos sociales) antes de que los medios los construyan" (Verón, 1983 [1987]:13).

Nos importan las alteraciones de escala en los procesos comunicacionales desatados por la muerte de Duré. Desde nuestro punto de vista no es lo mismo una dirección comunicacional ascendentehorizontal-transversal como la que se daba en la fase 1 que este estadio posterior, que designamos fase 3. Y es crucial distinguirlos ya que cada uno expresa el tipo particular de comunicación mediatizada. La fase 1 es plenamente contemporánea. La fase 2 al intervenir un enunciador "poderoso" se da un salto intrasistémico y la dirección deja de ser solo horizontal y también se vuelve descendente pero el colectivo está concentrado en las "redes"; cuando el discurso pasa a los medios masivos hay un salto intersistémico y millones de individuos que por múltiples razones no utilicen las "redes" también podrán ser interpelados, pero bajo la lógica propia de los medios masivos: el broadcasting (uno para muchos).

Ilustramos la fase 3 de la siguiente manera:

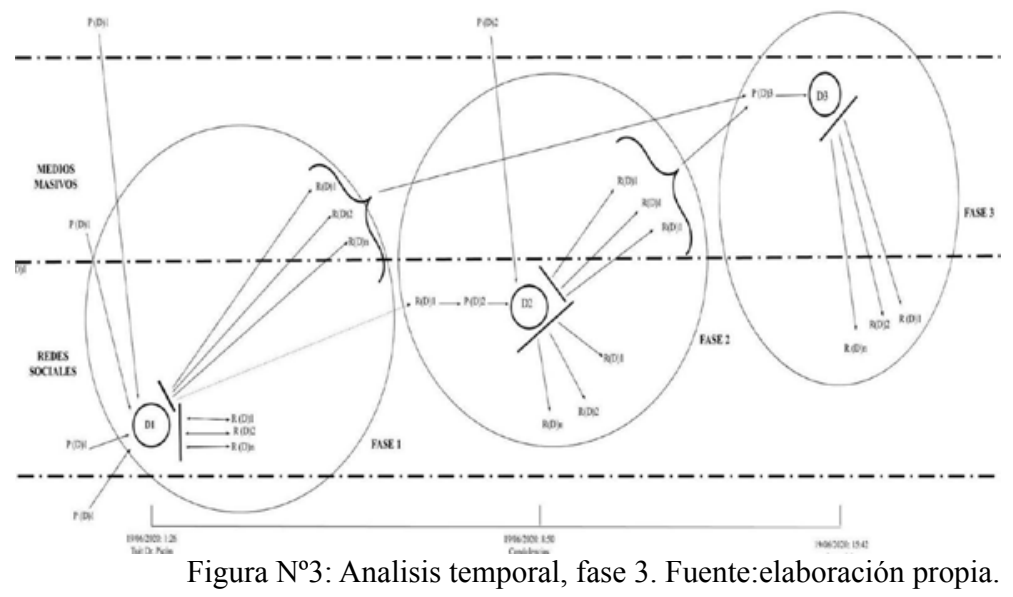

Dos décadas atrás las superficies mediáticas eran gestionadas exclusivamente por las instituciones mediáticas en una economía de escasez en la oferta discursiva. La internet 2.0 cambió el escenario, alterando las condiciones de circulación. Sin embargo, aunque hayan perdido la capacidad de programar la vida social (Verón,2009:245), los medios masivos siguen siendo importantes en la creación y reforzamiento de los colectivos (Verón,2013:422).

30 Durísima carta de los médicos residentes del perrando tras la muerte del jefe de terapia intensiva Miguel Duré (19 de junio de 2020$).$ Recuperado de: http://www.momarandu.com/notix/noticia/10293_dursima-carta-de-mdicos-residentes-del-perrando-tras-la-muertedel-jefe-de-terapia-intensiva-miguel-dur.htm 


\section{Volumen 1 \\ año 2020 \\ "Semiótica en Tiempos de PANDEMLA y POS/PANDEMLA"}

\section{Artículo}

Relssta del grupo de

Estudios SEMIO-DISCURSNOS

\section{| 2.5. "Bosteros de raza"}

Identificamos una subfase que comienza a las 10:38 am del 19 de julio cuando el internauta Ricardo Martínez publica en su muro de Facebook el siguiente posteo:

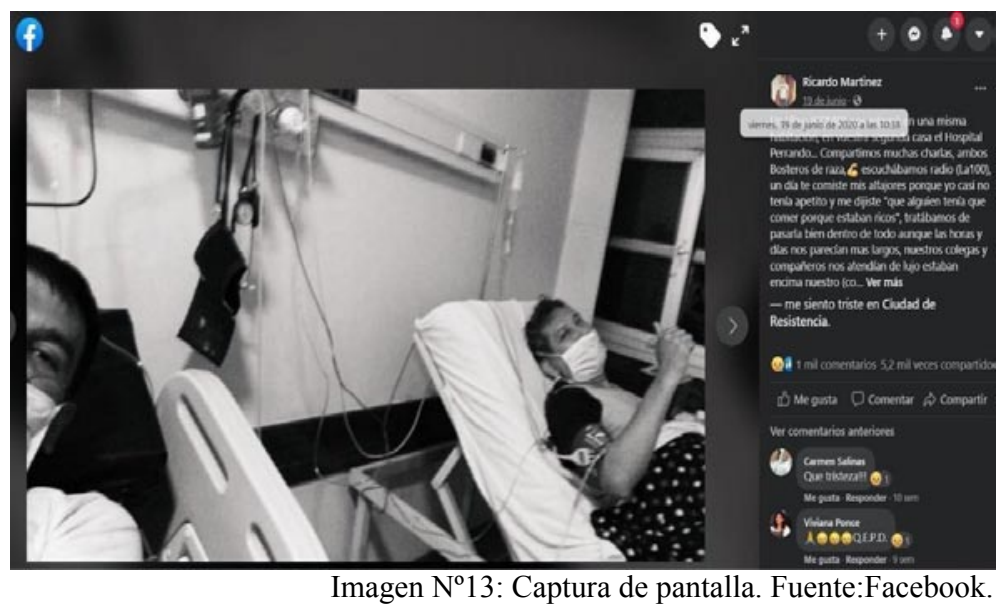

Unas 6.000 personas reaccionaron a la publicación, más de 5.200 compartieron el posteo y otras 1.000 hicieron comentarios. Martínez inserta el estado: "Me siento triste", esta operación es funcional mediante un mecanismo específico de Facebook como soporte mediático. El enunciador funda y legitima el sentimiento en los co-enunciadores que están en recepción en parte gracias a esa operación que podríamos denominar de "pathos explícito" (Amossy,2000:6). Es una diferencia de anteriores enunciadores examinados que no recurrieron a esta posibilidad en su estrategia enunciativa. No obstante al igual que Picón y Capitanich hay una dimensión de creencia de que el enunciador es quien dice ser y ha vivido (o siente) lo que ha publicado ${ }^{31}$.

Hay un relato -una narrativa de género vivencial- con fuerte carga emotiva que justifica el sentimiento de tristeza desde el recuerdo: "Compartimos muchas charlas, ambos Bosteros de raza, escuchábamos radio". Hay revelaciones de la intimidad de una internación hospitalaria: Martínez ingresa procesos mentales a la mediatización, lo que supone su inserción en espacios públicos. En esta subfase el colectivo se focaliza en torno al enunciado de Martínez, quien es un internauta más, que interactúa con los demás respondiendo comentarios con agradecimientos. La dirección de la comunicación es otra vez horizontal y los límites entre lo privado, lo íntimo y lo público se vuelven difusos, hay circulación transversal desde "afuera" hacia "adentro" de espacios no mediatizados a superficies mediáticas. 


\section{Artículo}

Revista del grupo de

Estudios SEMIO-DISCURSNOS

La subfase 1 la esquematizamos del siguiente modo:

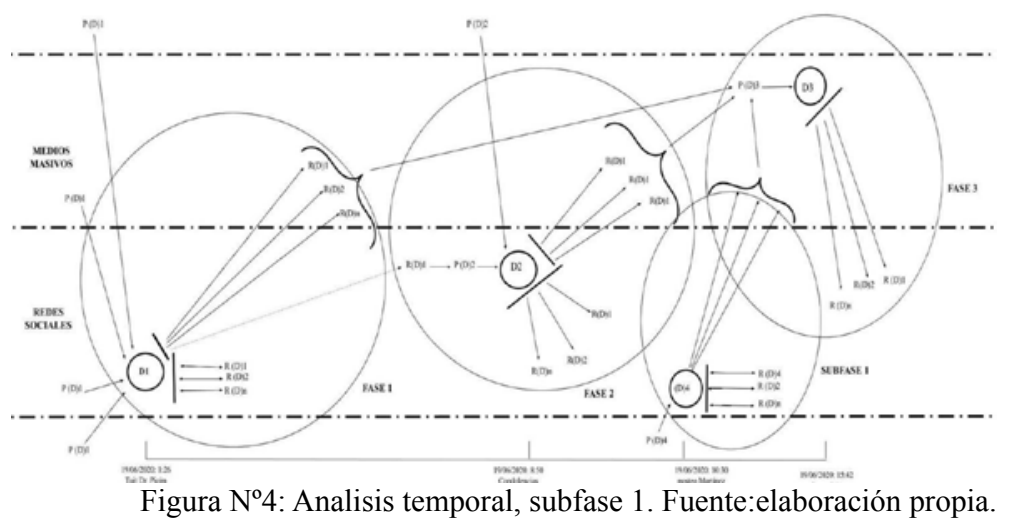

Martínez sube una fotografía privada -un autorretrato- que opera como trasposición en el pasaje de un estadio privado a otro público gracias al reconocimiento de los co-enunciadores de un "presente compartido" (Carlón,2015:47) y mediante múltiples reconocimientos discursivos posibles ("reacciones" 32 , comentarios, compartidos, capturas de pantalla,etcétera) ¿Qué tipo de foto es? Es una típica fotografía amateur, la dominante en la era contemporánea pero que convive con la de las otras épocas (Carlón,2015:49). La foto, pese a las condiciones de circulación contemporánea, es también moderna pues cumple la función de registro o testimonial, captura el tiempo. Sin embargo es contemporánea porque contiene prácticas propias de los internautas como la intervención, en este caso pasarla al blanco y negro. Esta "indicialidad débil” (Carlón, 2016a:162) es resultado de las operaciones de edición que habilita la digitalización fotográfica: un simple filtro en un celular desde una mirada semiótica comporta una operación discursiva de significación por parte del productor del discurso ya que puede imprimir aspectos "subjetivos" como decidir la gama cromática en desmedro de las condiciones lumínicas de su captura para referir un estado anímico. Además antes resultaban costosos o imposibles por las restricciones del propio aparato técnico.

Como resalta Carlón (2015), si en su apogeo el dispositivo fotográfico articuló naturaleza, sociedad y maquinismo, en la era contemporánea está experimentado un "giro antropocéntrico": las fotografías dejan de ser "medios de registro" para convertirse gracias a la digitalización en "medios de expresión". El sujeto, merced al software de edición, altera la fotografía y cortocircuita su indicialidad.

Seis horas después del posteo, DataChaco y Diario 21 publican entrevistas con Martínez, donde destaca la figura de Duré y revive la convivencia que mantuvieron. La nota incluso inserta la selfie y fragmentos íntegros del posteo. Es una de las tantas retomas del sentido producido en las redes que realizaron los medios masivos 


\section{Volumen 1

\section{Artículo}

Revista del grupo de

Estudios SEMIO-DISCURSNOS

\section{| 2.6. El regreso a los marcos institucionales}

Otra fase -llamada aquí fase 4- inicia a las 9:43 am del 20 de junio de 2020 cuando el gobernador de Chaco, Capitanich, realiza una conferencia de prensa televisada anunciando mejoras para los trabajadores de la salud pública, en respuesta a las conversaciones que mantuvo con los referentes del sector. Hacia el final de la presentación de 45 minutos, menciona a Duré reiterando su "dolor" y reafirmando su condición de "cristiano creyente". Sin embargo, lo que predomina es una argumentación racional para arribar a la conclusión de que "el gobierno no es responsable". Capitanich se vale de datos estadísticos y términos técnicos para argumentar.

El discurso de Capitanich construye un adversario impreciso: la "operaciones políticas" que "atacan" su persona. Una de sus frases sintetiza bastante: "Observamos que las críticas son todas discursos vacíos de contenido, que apelan a la culpabilidad política". Desde la razón intenta persuadir sobre los sentimientos de "esfuerzo" y "sacrificio" del gobierno que conduce frente a un "problema mundial" que "ningún país del mundo, ni las potencias mundiales ha podido controlar".

¿Qué cambió respecto de la primera intervención de Capitanich? Desde el punto de vista de la mediatización, mucho. La producción discursiva tiene otra lógica: la del directo televisivo (típica discursividad de los medios masivos), es una conferencia en vivo y televisada por la señal estatal de noticias (Chaco Tv) donde Capitanich está al amparo de los "marcos institucionales". Por ejemplo, la conferencia contaba con una presentadora (a la que no se ve, solo se oye) quien medió entre los periodistas y el gobernante leyendo las preguntas de los primeros (ninguna de las cuales mencionó a Duré explícitamente). Capitanich está en un atrio, detrás las banderas nacional y provincial y el escudo chaqueño, de fondo hay un panel blanco, a su derecha la vicegobernadora, Analía Rach (quien queda fuera de la escena cuando el plano se cierra). La escena da protección y seguridad al cuerpo del gobernante ante la indicialidad del directo, al menos, en una transmisión televisiva tradicional.

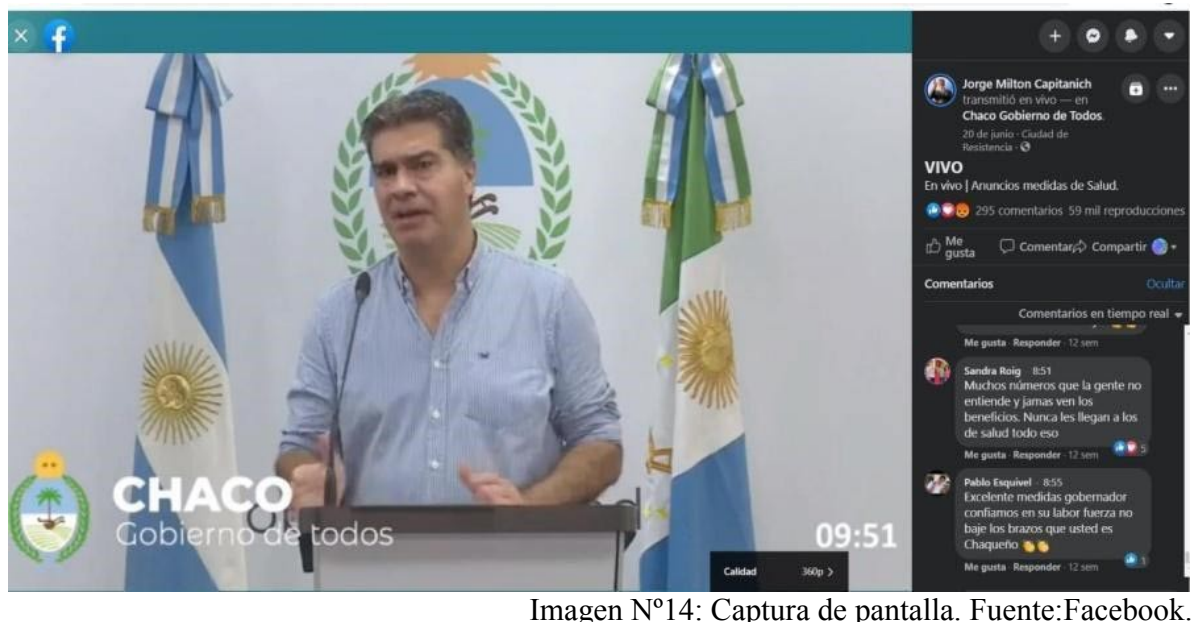

Imagen $\mathrm{N}^{\circ} 14$ : Captura de pantalla. Fuente:Facebook. 


\section{Volumen 1

Ahora bien, también la conferencia fue transmitida en vivo vía Facebook ${ }^{33}$. El lenguaje sigue siendo el mismo (directo televisivo) pero las condiciones de circulación nos obligan a que distingamos entre una transmisión por el canal oficial de televisión -con su lógica broadcasting- y lo que es Facebook Live, que habilita operaciones de producción discursivas mediáticas simultáneas ${ }^{34}$.

Representamos la fase 4 con la siguiente figura. En ella decidimos ubicar el discurso objeto (D) apenas por encima de la línea que separa medios masivos de redes sociales intentando resaltar esa interacción entre la transmisión por televisión y por Facebook Live:

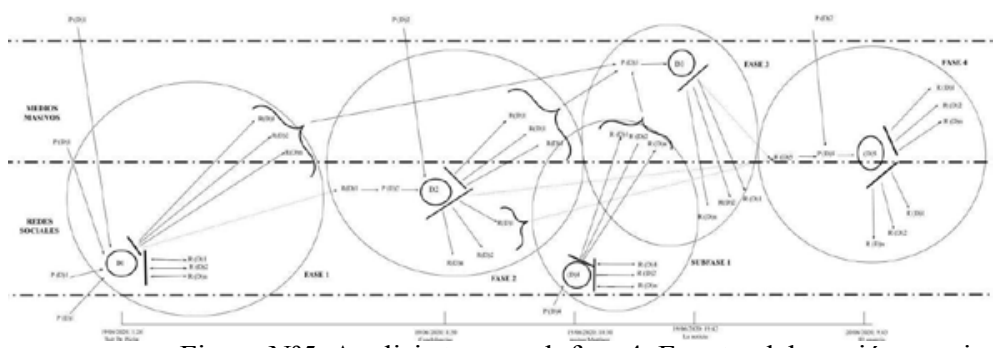

Figura $\mathrm{N}^{\mathrm{0}} 5$ : Analisis temporal, $\overline{\text { fase }} 4$. Fuente:elaboración propia.

Frente al televisor uno puede reaccionar de mil maneras pero ninguna implica una producción de discursividad mediática, allí la asimetría resulta patente. En cambio Facebook Live permite comentar en "tiempo real", es un discurso televisivo convergente (Carlón,2012:181) donde advertimos una triple interacción: comentarios sobre lo que dice Capitanich (a favor o en contra), comentarios sobre lo que dicen otros internautas (a favor o en contra) o comentarios ajenos a la conversación. Estas tres posiciones coinciden con las figuras del pro-destinatario, contra-destinatario y para-destinatario.

\section{7. "Una última despedida"}

El cierre de nuestra línea de tiempo para este análisis temporal es el 23 de junio de 2020 a las 17:38 pm. Transcurrido 4 días del fallecimiento del doctor Duré, su hijo Matías Duré, hace una publicación en su cuenta personal de Facebook ${ }^{35}$ que fue compartida por 3.445 usuarios, tuvo más de 7.000 reacciones y más de 1.000 comentarios:

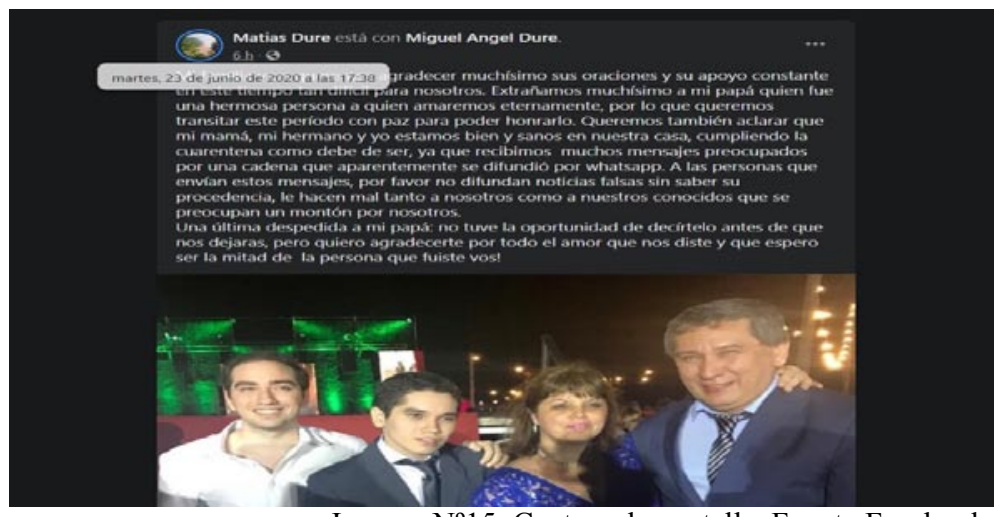

Imagen $\mathrm{N}^{\circ} 15$ : Captura de pantalla. Fuente:Facebook. 
La denominaremos subfase 2. Es -a nuestro entender- el momento de la circulación en que la mediatización de la vida social alcanza su máxima expresión: un enunciador amateur, desconocido hasta el momento, despide a su padre fallecido y genera reconocimiento en las redes y en los medios masivos. El enunciador lleva a cabo varias operaciones habilitadas por Facebook: etiqueta a la cuenta de su padre (lo convoca), sube una foto familiar con él y escribe: "Queremos transitar este período con paz para poder honrarlo". Advertimos -mediatizada en las redes- las tres dimensiones de la semiosis: la indicialidad del nombre propio, la iconicidad fotográfica y lo simbólico de la palabra escrita.

Se introduce en el espacio público mediático la intimidad de la relación padre-hijo (una dimensión que hasta entonces apareció muy poco, las valoraciones corrían por el lado profesional). La fotografía familiar no tenía -en la modernidad y posmodernidad- estatus de "medio" por no cumplir estrictamente con el carácter público, ya que solo se la muestra a unos pocos. El álbum familiar "hace posible, por primera vez, la puesta en representación de aquello que lo privado tiene de comunitario"(Verón,1997b:7) pero en la era contemporánea la fotografía está sometida a una "función comunicacional" que ante todo sirve para significar y hacer más intenso el momento que se vive (Carlón,2015:47). Así una revelación sumamente íntima como "no tuve la oportunidad de decírtelo antes de que nos dejaras" es leída (en reconocimiento) por miles de otros internautas.

El párrafo final del posteo comienza así: "Una última despedida a mi papá”. Sin embargo, luego, el enunciador hace un ajuste al registro y pasa a entablar un diálogo "personal" con su padre evocado: "Quiero agradecerte por todo el amor que nos diste". Un fragmento de intimidad -el comienzo del duelo- de un joven ignoto es "presenciado" por miles de otros internautas que conformando un colectivo responden reconfortándolo: es un discurso que no configura adversario.

Una parte del colectivo se construye sobre la base del estado de salud de la familia de Duré ya que circularon "noticias falsas" de que estaban enfermos y no cumplían el aislamiento: "Estamos bien y sanos en nuestra casa (...) recibimos muchos mensajes preocupados por una cadena que se difundió

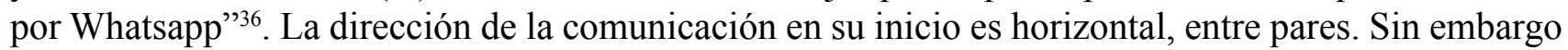
el posteo en Facebook -como la materialización de procesos mentales- cobra autonomía y persistencia temporal con la mediatización (Verón, 2013:235). Es así que vemos horas más tarde que los medios masivos tomaron la publicación de Matías Duré para replicarlas en sus páginas.

Ilustramos la subfase 2 con la figura $\mathrm{N}^{\circ} 6$ :

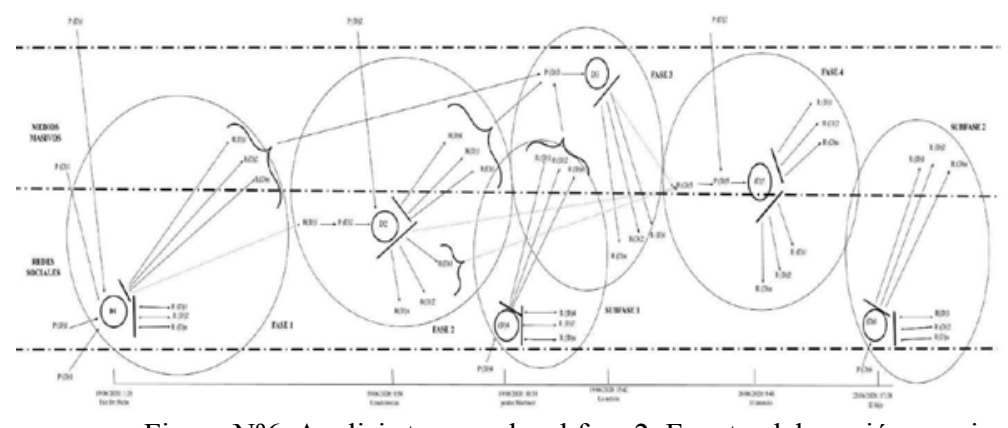

Figura No6: Analisis temporal, subfase 2. Fuente:elaboración propia.

En la figura $\mathrm{N}^{\mathrm{o}} 6$ se despliega toda la secuencia temporal que hemos venido describiendo. Podemos advertir que en tres de los seis momentos -fase 1, subfases 1 y 2 - la dirección comunicacional es horizontal-ascendente, propia de la contemporaneidad.

36 Resulta imposible en este espacio hacer referencia a dónde ubicar a Whatsapp. La tesis de graduación en desarrollo cuenta con dos casos que tienen el inicio de su circulación a esta "sistema de mensajería". Carlón considera que es el "underground de los sistemas mediáticos, debajo del espacio en el que ubicamos a redes sociales mediáticas como Instagram, Facebook y Twitter debido a que posee características específicas”(Carlón, 2020:106). 


\section{Artículo}

Revista del grupo de Estudios SEMIO-DISCURSNOS

\section{| 2.8. Análisis espacial}

Nos detendremos en el análisis espacial para describir las reconfiguraciones en el colectivo a partir de un momento clave: las condolencias de Capitanich (fase 2). La razón fundamental es que al enunciar Capitanich se reacomodan las posiciones en que estaban dispuestos otros enunciadores. Agrupandolos según la clasificación propuesta por Carlón (2020) y su equipo de cátedra (Carlón et. al., 2017) podemos representar el momento previo a la intervención enunciativa de Capitanich en la circulación del siguiente modo:

\section{ANTES DE LAS CONDOLENCIAS DE CAPITANICH}

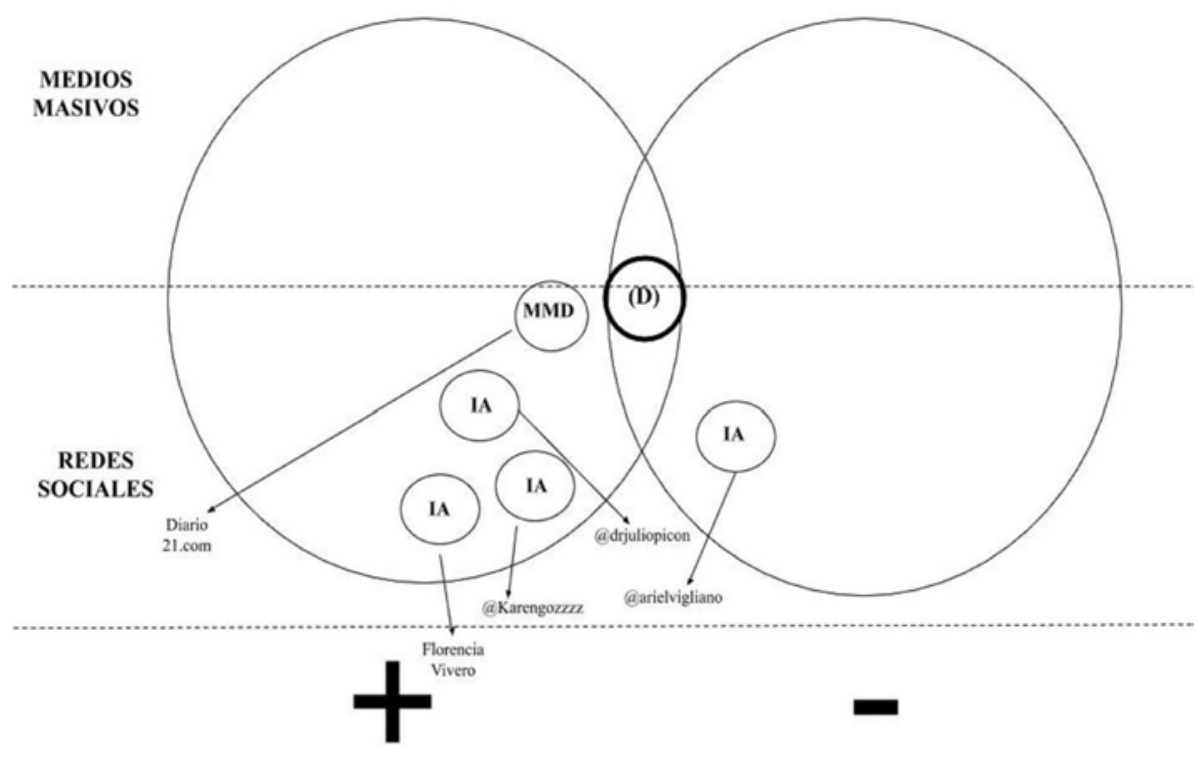

Figura No7: Analisis temporal, fase 4. Fuente:elaboración propia.

Mediante esta representación se vuelve observable el lugar que ocuparon los enunciadores en el momento previo a la intervención de Capitanich. Los individuos amateur (IA) son el principal componente del colectivo. Sus enunciados son mayoritariamente empáticos, salvo algunos como@ arielvigano quien tuiteó: "A esta altura me imagino que el Capitanich ya dirimió". También se aprecia que la retoma de los medios masivos (MM) y medios masivos digitales (MMD) es baja. 
Con la figura $\mathrm{N}^{\mathrm{o}} 8$ representamos el después de las condolencias:

\section{DESPUÉS DE LAS CONDOLENCIAS DE CAPITANICH}

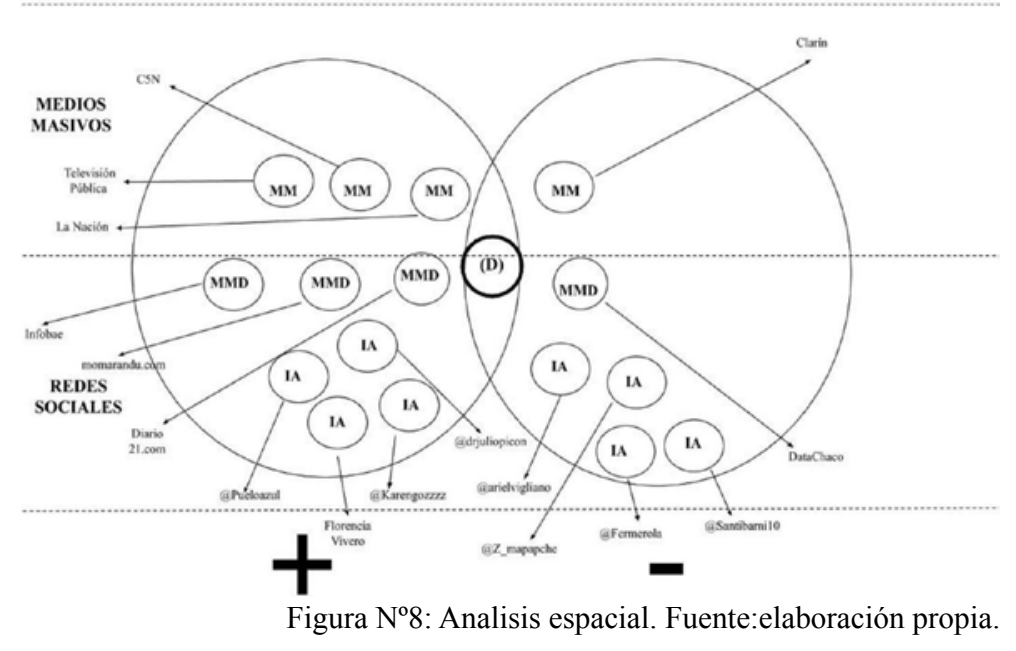

Por un lado vemos el incremento de la posición de los IA en una postura crítica frente al discurso de Capitanich, que lo rechazan por "caradura". Sin embargo, como se dijo, el colectivo es heterogéneo y otros miembros también IA se mantienen en una posición de reconfortación y aliento, de dolor compartido por la muerte del doctor Duré. Los MM y los MMD también se ubican desde ese lugar resaltando la figura de Duré antes que "politizar" el tema. Justamente los que "politizan" el tema desde lo pasional son ese conjunto de IA que reaccionó negativamente ante el gesto del gobernante.

Con esto intentamos hacer ver que los colectivos hipermediáticos se configuran en una complejidad creciente disputando sentido en el espacio mediático. Vemos cómo en un primer momento el sentido configura un colectivo principalmente movilizado por el dolor causado por la muerte y la necesidad de algunos de construir en Capitanich un adversario pero luego ocurre una fragmentación y este "segmento" del colectivo crece notoriamente en reacción a la enunciación del gobernador. Estas reconfiguraciones son puestas en juego por el poder de la circulación, que hace que el sentido cambie permanentemente de dirección y lógica alterando de un momento a otro la composición del colectivo.

\section{Conclusión}

En sus últimos años, Eliseo Verón avanzó hacia una teoría no antropocéntrica de la mediatización, sin embargo siempre sostuvo que la construcción de colectivos en el seno de la comunicación mediática era un atributo de las instituciones y de los medios masivos. Los sistemas socioindividuales, por la temporalidad de los ciclos de vida, no podrían construir colectivos (Verón,2013:431). Pero en la era contemporánea en la que estamos ingresando -y que la pandemia ha acelerado- los individuos mediatizados construyen colectivos que crecen, se modifican e implosionan. La temporalidad del ciclo de vida cobra un valor excepcional en la historia de la mediatización debido a que el presente se experimenta con una intensidad mayor, lo cotidiano se vuelve cada vez más significativo porque se lo puede compartir con miles de otros en co-presencia. La descripción que hemos realizado nos permitió mostrar el poder de la circulación: vimos como enunciadores amateurs construyen colectivos a partir 
de introducir fragmentos de su vida personal en el espacio mediático de las redes pero también el modo en que un enunciador poderoso intenta generar un "efecto de sentido" otros enunciadores lo rechazan con argumentos, agravios y también humor.

El final de un ciclo de vida puede ser el inicio de un colectivo. Las condiciones actuales de mediatización nos obligan a considerar la temporalidad finita del individuo biológico porque lo que ha cambiado es la percepción del transcurso del tiempo y el valor de la vida adquiere hoy -en tiempos de pandemia- un nivel superlativo. Pero si por un lado debemos contemplar la relación individuosociedad-naturaleza, por el otro hay que atender a la relación individuo-sociedad-máquina porque ahora que cualquiera cuenta con medios individuales ocurre un "giro antropocéntrico" en la historia de la mediatización: se abandona el proyecto de representar fielmente, de registrar naturaleza y sociedad; lo maquinístico pasa a cumplir una función expresiva (Carlón,2016a:162). Es por ello que debemos seguir avanzando en la elaboración de una teoría no antropocéntrica de la mediatización que nos permita conceptualizar el complejo escenario que enfrentamos al contemplar el advenimiento de la era contemporánea.

\section{Bibliografía}

Amossy R.(2000). L'argumentation dans le discours. París, Nathan.

Carlón, M.(2020). "Del poder de los enunciadores al poder la circulación. Enunciadores hipermediáticos, dimensión espacial y procesos de la comunicación” (P.p.97-158). En Carlón M. (2020). Circulación de sentido y construcción de sentido. San Luis, Nueva Editorial Universitaria.

Carlón, M.(2020). "La circulación transversal: desde 'adentro hacia afuera' y desde 'afuera hacia adentro' de los individuos, los colectivos y las instituciones sociales” (P.p.159-174). En Carlón M.(2020). Circulación de sentido y construcción de sentido. San Luis, Nueva Editorial Universitaria.

Carlón, M.(enero-junio, 2019). Individuos y colectivos en los nuevos estudios sobre circulación. InMediaciones de la comunicación, (14), 27-46. DOI: https://doi.org/10.18861/ic.2019.14.1.2884

Carlón, M.(2018). "Medios individuales, medios colectivos y circulación transversal" (P.p.2646). En Paulo Cesar Castro (2018). Circulação discursiva e transformação da sociedade. Campina Grande, Eduepb.

Carlón, M.(2016a) "El marco teórico: una perspectiva no antropocéntrica de la mediatización" (P.p.9-38). En: Carlón M. (2016a). Después del fin. Una perspectiva no antropocéntrica sobre la posttv, el post-cine y YouTube. Buenos Aires, La Crujía.

Carlón, M.(2016a) "Ataque a los poderes, medios convergentes y giro antropocéntrico: el nuevo escenario con base en Internet” (P.p.147-172). En: Carlón M. (2016a). Después del fin. Una perspectiva no antropocéntrica sobre la post-tv, el post-cine y YouTube. Buenos Aires. La Crujía.

Carlón, M.(2016b) "Apropiación contemporánea de la teoría comunicacional de Eliseo Verón" (P.p.125-153). En Vizer E. y Vidales C. (2016). Comunicación, Campo(s), Teorías y Problemas. Una Perspectiva Internacional. Salamanca, Comunicación Social.

Carlón, M.(2015) "Registrar, subir, comentar, compartir: prácticas fotográficas en la era contemporánea” (P.p.31-54). En Corro P. y Roble C.(2015). Estética, medios masivos y subjetividades. Santiago, Pontificia Universidad Católica de Chile.

Carlón, M.(2012). "En el ojo de la convergencia. Los discursos de los usuarios de Facebook durante la transmisión televisiva de la votación de la ley de matrimonio igualitario" (P.p.173-194). En: Carlón M. y Fausto Neto A. (2012). La política de los internautas. Nuevas formas de participación. Buenos Aires, La Crujía. 
Carlón, M.(2010). “¿Del arte contemporáneo a una era contemporánea? Efecto arte y el nuevo valor del presente en la era de internet" (P.p.187-211). En Rovetto F. y Reviglio M. (2010). Estado actual de las investigaciones en mediatizaciones. Rosario, Editorial UNR.

Carlón, M. (2009). "Maquinismo, naturaleza y sociedad en el discurso de las cámaras de informes climáticos y de control de tránsito por televisión”. En: CIC Cuadernos de información y comunicación (13), 131-141. Recuperado de: https://revistas.ucm.es/index.php/CIYC/article/view/ CIYC0808110131A

Carlón M., Fraticelli D., Slimovich A. y Jiménez M.(2017). Documento Teórico Metodológico de la Cátedra Semiótica de Redes de la Carrera de Ciencias de la Comunicación de la Universidad de Buenos Aires. Recuperado de: http://semioticaderedes-carlon.com/wp-content/uploads/2016/03/TPDOC-2017-CATEDRACARLON-UBA.pdf

Castells M. (2009). Comunicación y poder. Madrid, Alianza Editorial.

Culioli A.(2010). "Estabilidad y deformabilidad en lingüística" (P.p.111-128). En Culioli A. (2010). Escritos. Buenos Aires, Santiago Arcos Editor.

Maingueneau D.(2009). Análisis de textos de Comunicación. Buenos Aires, Nueva Visión.

Schaeffer J.M.(2007). El fin de la excepción humana. México, Fondo de Cultura Económica.

Sigal, S. y Verón E.(2009). Perón o Muerte. Los fundamentos discursivos del fenómeno peronista. Buenos Aires, Eudeba.

Slimovich, A.(2012) "El Facebook de los gobernantes. El caso de Cristina Fernández de Kirchner y Mauricio Macri” (P.p.137-154). En Carlón M. y Fausto Neto A. (2012). Las políticas de los internautas. Nuevas formas de participación. Buenos Aires, La Crujìa.

Verón E.(2013) "Ciclos de vida" (P.p.421-432). En Verón (2013). La semiosis social 2. Ideas Momentos, Interpretantes. Buenos Aires, Paidós.

Verón E.(2013) "Lógicas sistémicas sociales y socioindividuales" (P.p.291-304). En Verón (2013). La semiosis social 2. Ideas Momentos, Interpretantes. Buenos Aires, Paidós.

Verón E.(2013) "La mediatización de la temporalidad” (P.p. 249-260). En: Verón (2013) La semiosis social 2. Ideas Momentos, Interpretantes. Buenos Aires, Paidós.

Verón E.(2013) "Interludio: las alteraciones de escala" (P.p.243-248). En: Verón (2013) La semiosis social 2. Ideas Momentos, Interpretantes. Buenos Aires, Paidós.

Verón E.(2009). "El fin de la historia de un mueble" (P.p. 229-250). En: Carlón M. y Scolarí C. (2009) El fin de los medios masivos. El comienzo de un debate. Buenos Aires, La Crujía

Verón E.(2001). "El Living y sus dobles. Arquitectura de la pantalla chica" (P.p. 13-40). En: Verón, E. (2001) El cuerpo de las imágenes. Buenos Aires, Grupo Norma.

Verón E.(1997a). Esquema para el análisis de la mediatización. Diálogos de la comunicación (48) 10-17. Recuperado de: https://halshs.archives-ouvertes.fr/halshs-01488522/document

Verón E.(1997b) "De la imagen semiológicas a las discursividades. Los tiempos de una fotografía" (P,p.47-70). En: Veyrat-Masson I. y Dayan D. (1997). Espacios Públicos en Imágenes. Barcelona, Gedisa.

Verón E.(1994). "La mediatización de lo político. Estrategias, actores y construcción de los colectivos" (P.p. 220-236). En: Gauthier, G. Gosselin A. y Mouchon J. (1994). Comunicación y Política. Barcelona, Gedisa.

Verón E.(1987) "La clausura semiótica" (P.p. 111-120). En: Verón (1987). La semiosis social. Fragmentos de una teoría de la discursividad. Barcelona, Gedisa.

Verón E.(1987) "El sentido como producción discursiva" (P.p. 124-133). En: Verón (1987). La semiosis social. Fragmentos de una teoría de la discursividad. Barcelona, Gedisa.

Verón E.(1987) "El cuerpo reencontrado" (P.p. 140-156). En: Verón (1987) La semiosis social. Fragmentos de una teoría de la discursividad. Barcelona, Gedisa. 
Verón E.(1986). La Mediatización. Buenos Aires, Facultad de Filosofía y Letras UBA.

Verón E.(1984). Semiosis de lo ideológico y del poder. Espacios (1) 43-51. Recuperado de: https://halshs.archives-ouvertes.fr/halshs-01484189/document

Verón E.(1983[1987]). Construir el acontecimiento. Los medios de comunicación masiva y el accidente en la central nuclear Three Miles Island. Barcelona: Gedisa. 